\title{
Correlates of Suicide Ideation and Attempt among Youth Living in the Slums of Kampala
}

\author{
Monica H. Swahn ${ }^{1, *}$, Jane B. Palmier ${ }^{1}$, Rogers Kasirye ${ }^{2}$ and Huang Yao ${ }^{1}$ \\ 1 Institute of Public Health, Georgia State University, P.O. Box 3995, Atlanta, GA 30302, USA; \\ E-Mails: janepalmier@gamail.com (J.B.P.); sawsinnj@gmail.com (H.Y.) \\ 2 Uganda Youth Development Link, P.O. Box 12659, Kampala, Uganda; \\ E-Mail: kasiryer@yahoo.com \\ * Author to whom correspondence should be addressed; E-Mail: MSwahn@gsu.edu; \\ Tel.: +1-404-413-1148.
}

Received: 28 December 2011; in revised form: 21 January 2012 / Accepted: 6 February 2012 / Published: 16 February 2012

\begin{abstract}
While suicidal behavior is recognized as a growing public health problem world-wide, little is known about the prevalence and risk factors for suicidal behaviors among street and slum youth in Africa, and in Uganda, specifically. The number of youth who live on the streets and in the slums of Kampala appears to be growing rapidly, but their mental health needs have not been documented, which has hampered resource allocation and service implementation. This study of youth, ages 14-24, was conducted in May and June of 2011, to assess the prevalence and correlates of suicidal behavior. Participants $(N=457)$ were recruited for a 30-minute interviewer-administered survey through eight drop-in centers operated by the Uganda Youth Development Link for youth in need of services. Bivariate and multivariate logistic regression analyses were computed to determine associations between psychosocial correlates and suicide ideation and suicide attempt. Reporting both parents deceased Adj.OR = 2.36; 95\% CI: 1.23-4.52), parental neglect due to alcohol use (Adj.OR $=2.09 ; 95 \%$ CI: 1.16-3.77), trading sex for food, shelter or money (Adj.OR $=1.95 ; 95 \% \mathrm{CI}: 1.09-3.51)$, sadnesss $($ Adj.OR $=2.42 ; 95 \% \mathrm{CI}$ : 1.20-4.89), loneliness (Adj.OR $=2.67 ; 95 \% \mathrm{CI}: 1.12-6.40$ ) and expectations of dying prior to age 30 (Adj.OR $=2.54$; 95\% CI: $1.53-4.23$ ) were significantly associated with suicide ideation in multivariate analyses. Parental neglect due to alcohol use (Adj.OR $=2.04$; 95\% CI: 1.11-3.76), sadness (Adj.OR $=2.42 ; 95 \% \mathrm{CI}: 1.30-7.87$ ), and expectations of
\end{abstract}


dying prior to age 30 (Adj.OR $=2.18$; 95\% CI: $1.25-3.79$ ) were significantly associated with suicide attempt in multivariate analyses. Given the dire circumstances of this vulnerable population, increased services and primary prevention efforts to address the risk factors for suicidal behavior are urgently needed.

Keywords: suicidal ideation; suicide attempt; street youth; homeless youth; vulnerable youth; adolescents; sadness; loneliness; parental neglect; trading sex; Africa; Uganda; Kampala

\section{Introduction}

Every year, almost one million people die from suicide; a global mortality rate of 16 per 100,000, or one death every 40 seconds [1] and as such it is a critically important public health problem [2]. Suicide is the fourth leading cause of death globally among youth 15 to 19 years of age [3] and the tenth leading cause for adolescents 10-14 years of age [4]. However, these figures do not include suicide attempts, which are up to 20 times more frequent than completed suicide [1]. Research on suicidal behavior specifically in Africa has been scarce [5,6], in part because of other pressing health concerns, but also because of political and economic instability [7].

Suicidal behavior in Africa was thought to be rare in the past, but recent studies suggest that it represents a substantial public health burden [5,6]. Studies conducted in Nigeria [8], South Africa [9], Zambia [10], and Uganda [5,11] indicate that suicidal behavior is relatively common, but also varies across countries [12]. For example, among school students, self-reported suicidal ideation ranges between 19.6\% in Uganda, 23.1\% in Botswana, 27.9\% in Kenya, and 31.9\% in Zambia [12]. Alcohol use and bullying victimization [12], as well as experiencing hunger [13], appear to be important risk factors for suicidal ideation. However, the high levels of suicidal ideation and behavior among youth in sub-Saharan Africa have likely been exacerbated by the severe psychosocial stress and other adverse health outcomes associated with the high prevalence of HIV/AIDS in Africa [2] as well as scarce food supply [14] and other distressing circumstances. In addition, the stigma, discrimination, isolation, lack of support from family and friends, loss of parents or family members from HIV/AIDS further increases the risk of suicidal behavior [7].

Youth who live on the streets and in the slums of sub-Saharan Africa face much of the burden related to poverty, lack of family support as well as infectious and chronic diseases [15,16]. However, there is a dearth of research on the specific health needs of these vulnerable youth and their strategies for coping and trying to survive under such dire circumstances. It has been noted that street children face complex issues, but also that more information is needed for resource allocation and the design and implementation of prevention and intervention efforts $[15,16]$. The health concerns of street children in Kampala is a particularly pressing issue because they are expected to substantially increase in numbers as Uganda is projected to have the world's highest population growth over the next couple of decades [17].

Depending on the age groups and definitions used, there are between 100 million and 300 million street youth worldwide, most of them in low- and middle-income countries [18-20]. Most of the 
world's street children are boys, although estimates of girls living on the streets range from one-fourth to one-third worldwide [21]. Throughout the world, poverty is the underlying cause of the high number of street children [21,22]. Substance abuse, mental and physical health problems among street youth appear to be a substantial problem and the provision of scarce medical and mental healthcare presents challenges to organizations working with this vulnerable population [19].

There is a dearth of information regarding the specific mental health needs and concerns among street youth in sub-Saharan Africa, but it is expected that youth who live on the streets and in the slums have high levels of suicidal ideation and behavior. Research from other countries may not be generalizable to sub-Saharan Africa, but may provide relevant context. A few studies of suicidal behavior among street youth in the U.S. and Canada have found that the prevalence of suicide attempt ranges between $20 \%$ and $40 \%[23,24]$ and that suicide was a leading cause of death in this population [25]. Abuse, whether physical, sexual or other victimization [23,24] is a key risk factor for suicide risk as is family substance abuse [23,26], youth substance use [23], social stigma [27], depression [23,24], low self-esteem and feeling helpless [28]. The underlying conditions for these problems have been attributed to abusive caretakers and to street culture which encourages high-risk behaviors such as alcohol and drug use, prostitution, stealing and drug dealing [24].

Given the dearth of research of the scope of mental health needs and concerns among youth who live on the streets and in the slums in sub-Saharan Africa, this study examines the prevalence and risk factors for suicidal ideation and attempt specifically among such youth in Kampala, Uganda. The purpose of this project is to obtain quantitative data to assess demographic characteristics, family context, psychosocial factors such as substance use, sexually transmitted diseases including HIV/AIDS, sadness and loneliness and their associations with suicide ideation and attempt in a convenience sample of service-seeking youth. Findings from this study can be used to quantify the scope of unmet needs in this vulnerable population and to seek resources and strategies to implement prevention and intervention strategies.

\section{Methods}

The overarching goal of the cross-sectional survey called the "Kampala Youth Survey", conducted in May and June 2011, was to quantify and describe high-risk behaviors and exposures in a convenience sample of urban youth living on the streets or in the slums, 14-24 years of age, who were participating in a Uganda Youth Development Link (UYDEL) [29]; drop-in center for disadvantaged street youth. UYDEL serves on average about 650 youth per month through these drop-in centers. Face-to-face surveys, lasting about 30 minutes, were administered by social workers/peer educators employed by UYDEL. The study was implemented across eight drop-in centers across Kampala. Participating youth received snacks and transportation for completing the survey. No identifying information was collected and the surveys were completely anonymous. Surveys were administered in English or Luganda, to the extent possible, in private settings and rooms, to ensure privacy of survey questions and responses.

Each social worker/peer educator received training on the study methodology, each of the survey questions and its translation into Luganda (local language) if needed, and recruited potential participants among attendants at their specific drop-in Center. Recruitment took place using word-of-mouth, and 
each attendant was eligible for participation if they were between 14 and 24 years of age. No exclusion criteria were applied beyond the age range. Participants were informed about the study and read (or were read) the consent forms to indicate their willingness to take the survey. The consent process required that emancipated street youth 14 to 17 years of age provide their own consent for participating in the survey (Because youth 14 to 17 years of age who "cater for their own livelihood" are considered emancipated in Uganda, parental permission/consent had been waived.) The same consenting process was followed for youth 18 to 24 years of age.

Over the ten-day survey period, 507 youth were approached for participating in the survey. Among these youth, 46 declined and 461 agreed to participate, yielding a participation rate of $90.9 \%$. Four of the surveys were missing substantial numbers of responses and were therefore excluded, yielding 457 completed surveys for the final analytic sample of youth between the ages of 14 and $24(31.1 \%$ boys and $68.5 \%$ girls). The mode for age was 17 years $(n=81)$ and $67 \%$ of participants were between ages 16 and 20 .

\subsection{Measures}

The survey questionnaire was modeled from existing surveys such as the U.S. based Youth Risk Behavior Survey [30] conducted by the Centers for Disease Control and Prevention and the international Global School-based Student Health Survey [31] supported by the World Health Organization and which provides data on health behaviors and relevant risk and protective factors among students across all regions served by the United Nations. The study development was also informed by training materials related to working with street children prepared by the World Health Organization [32]. Survey questions addressed demographic characteristics, family context, alcohol and drug use, injuries, violence and suicidal behaviors, sexual behaviors and sexually transmitted diseases, including HIV/AIDS.

The study protocol was approved by the Georgia State University Institutional Review Board and also by the Uganda National Council for Science and Technology. Funding to conduct the study were obtained from the Georgia State University Office of International Initiatives and also from funds leveraged through collaboration with the Emory Center for Injury Control, funded by the Centers for Disease Control and Prevention.

\subsection{Analysis}

The measures included in the analyses and their prevalence among study participants are described in Table 1. Bivariate and multivariate logistic regression analyses were computed to determine statistical association between suicide ideation and suicide attempt and demographic and psychosocial correlates using the SAS 9.2 and SUDAAN 10 statistical software packages. Moreover, all variables except for parental living were dichotomized to indicate the presence or absence of the particular risk factor. The reference category for each variable in the logistic regression analyses was the absence of the particular risk factor. 


\section{Results}

The demographic characteristics and family context of the participants are presented in Table 1 . With respect to family context, $76 \%$ of the participants had one or more deceased parent, $63 \%$ reported ever being hit or beaten by their parents and $21 \%$ reported that their parent's alcohol use had prevented them for providing care for them.

Table 1. Description of variables and their prevalence among youth living in the slums of Kampala $(N=457)$.

\begin{tabular}{|c|c|c|}
\hline Descriptive label & Variable Wording & Percentage \\
\hline School attendance & Percentage of youth who currently attend school & $14.4 \%$ \\
\hline Both parents dead & Percentage of youth with both parents dead & $39.6 \%$ \\
\hline One parent dead & Percentage of youth with mother or father dead & $36.3 \%$ \\
\hline Two parents living & Percentage of youth with both mother and father alive & $23.0 \%$ \\
\hline Parental physical abuse & $\begin{array}{l}\text { Percentage of youth who reported that their parents ever hit/beat them } \\
\text { (yes versus no) }\end{array}$ & $62.6 \%$ \\
\hline $\begin{array}{l}\text { Parental neglect due to } \\
\text { alcohol use }\end{array}$ & $\begin{array}{l}\text { Percentage of youth who reported their parents' alcohol use made them } \\
\text { not able to care for them (yes versus no) }\end{array}$ & $21.0 \%$ \\
\hline Apprenticeship skills & Percentage of youth who state that they have any apprenticeship skills & $56.0 \%$ \\
\hline Any drug use & $\begin{array}{l}\text { Percentage of youth who have ever used drugs such as marijuana (njaga } \\
\text { or bangi) or opium (njaye or sniffed aviation fuel (one or more days) }\end{array}$ & $13.8 \%$ \\
\hline Any drunkenness & Percentage of youth who have ever been really drunk (one or more days) & $32.6 \%$ \\
\hline Any STD/HIV & $\begin{array}{l}\text { Percentage of youth who have been told by a doctor or nurse that they } \\
\text { have a sexually transmitted infection, such as syphilis, bolabola or } \\
\text { gonorrhea, or that they have HIV/AIDS (yes versus no) }\end{array}$ & $37.2 \%$ \\
\hline Any traded sex & $\begin{array}{l}\text { Percentage of youth who have ever gotten money, food, or other things } \\
\text { for have sexual intercourse with someone (yes versus no) }\end{array}$ & $31.7 \%$ \\
\hline Any rape & $\begin{array}{l}\text { Percentage of youth who have ever been forced to have sex with } \\
\text { someone (yes versus no) }\end{array}$ & $24.1 \%$ \\
\hline Sadness & $\begin{array}{l}\text { Percentage of youth who ever felt so sad or hopeless almost every day } \\
\text { for two weeks in a row in the past year that they stopped doing their } \\
\text { usual activities (yes versus no) }\end{array}$ & $75.1 \%$ \\
\hline Loneliness & $\begin{array}{l}\text { Percentage of youth who have felt lonely in the past month } \\
\text { (sometimes/often versus never) }\end{array}$ & $81.8 \%$ \\
\hline Expect to die early & $\begin{array}{l}\text { Percentage of youth who think they will probably die before the age of } \\
\text { thirty (sometimes/often versus never) }\end{array}$ & $43.5 \%$ \\
\hline Suicidal ideation & $\begin{array}{l}\text { Percentage of youth who have thought of killing themselves in the } \\
\text { past year }\end{array}$ & $30.6 \%$ \\
\hline Suicide planning & $\begin{array}{l}\text { Percentage of youth who have thought about how they would kill } \\
\text { themselves in the past year. }\end{array}$ & $22.9 \%$ \\
\hline Suicide attempt & Percentage of youth who tried to kill themselves in the past year. & $19.8 \%$ \\
\hline $\begin{array}{l}\text { Suicide attempt } \\
\text { requiring medical help }\end{array}$ & $\begin{array}{l}\text { Percentage of youth who needed medical help after trying to kill } \\
\text { themselves in the past year. }\end{array}$ & $11.9 \%$ \\
\hline
\end{tabular}


In terms of schooling and skills, $14 \%$ were currently attending school and 56\% reported that they had acquired some apprenticeship skills. Loneliness, sadness, and expectations of dying before age 30 were reported by $82 \%, 75 \%$ and $44 \%$, respectively.

The overall prevalence of reporting suicide ideation (31\%), suicide attempt planning (23\%), suicide attempt (20\%), and a suicide attempt requiring medical treatment $(12 \%)$ and for boys and girls separately, are presented in Figure 1. The prevalence of suicide ideation was statistically higher for girls $(34 \%)$ than boys $(23.2 \%)(\mathrm{OR}=1.73 ; 95 \% \mathrm{CI}: 1.10-2.73)$. However, no other significant differences were observed between boys and girls in terms of having planned or made a suicide attempt or having required medical treatment following a suicide attempt.

Figure 1. Prevalence of suicidal ideation and suicidal behaviors for boys and girls living in the slums of Kampala $(N=457)$. * Girls were more likely than boys to report suicide ideation; OR $=1.73 ; 95 \%$ CI: $(1.10-2.73)$.

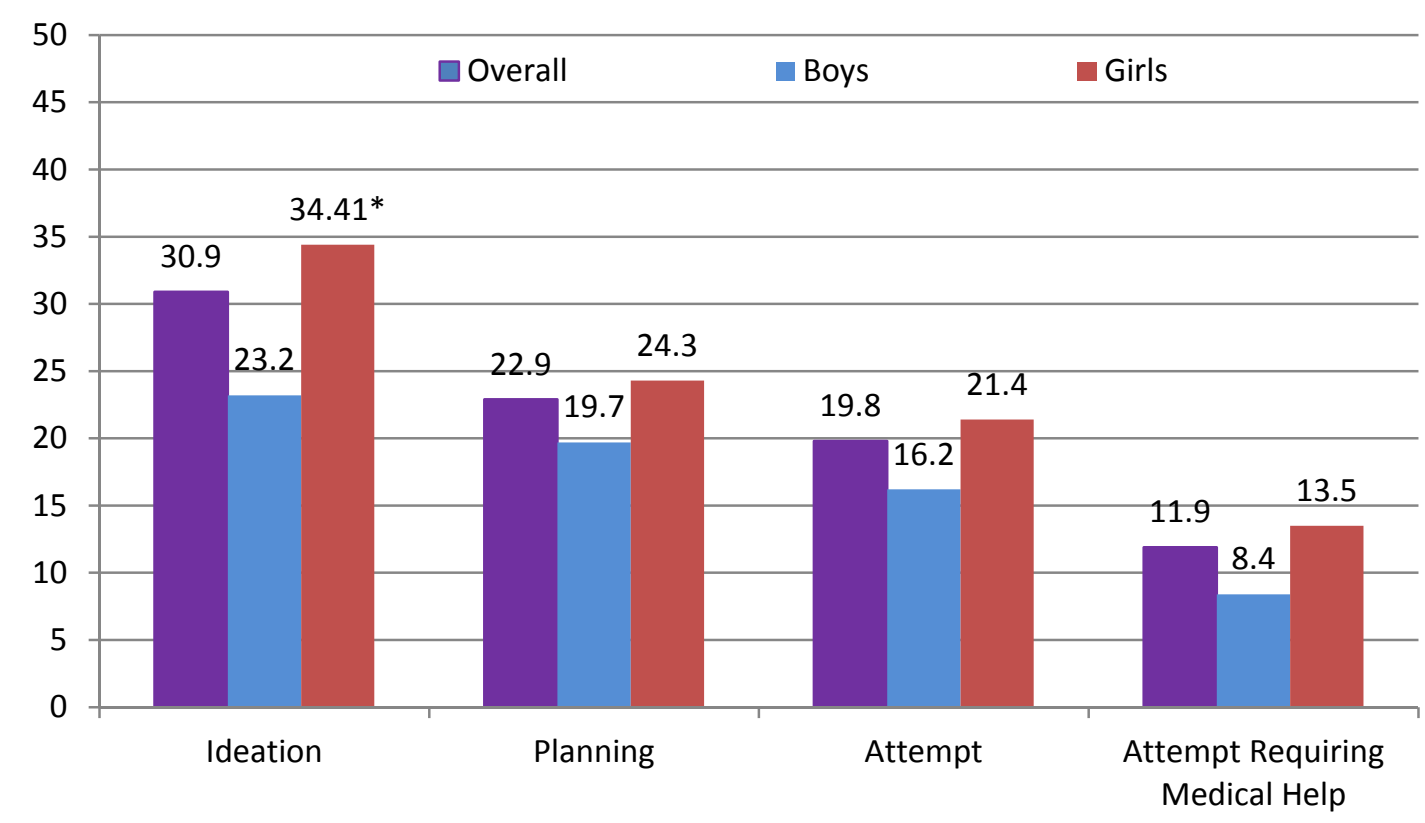

In the bivariate logistic regression analyses, having two deceased parents, reporting parental neglect due to alcohol use, any drug use, any drunkenness, any sexually transmitted diseases, any traded sex, sadness, loneliness, and an expectation of dying prior to the age of 30 were significantly associated with suicide ideation (Table 2). The psychosocial correlates that were significant in the bivariate analyses were entered into a multivariate regression analyses. The multivariate analyses show that having two deceased parents, parental neglect due to alcohol use, any traded sex, sadness, loneliness, and an expectation of dying prior to the age of 30 were significantly associated with suicide ideation (Table 2).

In the bivariate logistic regression analyses for suicide attempt, reporting parental neglect due to alcohol use, any drug use, any drunkenness, any sexually transmitted diseases/HIV, any traded sex, sadness, loneliness, and an expectation of dying prior to the age of 30 were significantly associated with the outcome (Table 3). Again, the psychosocial correlates that were significant in the bivariate analyses were entered into a multivariate regression analyses. The multivariate analyses show that 
parental neglect due to alcohol use, sadness, and an expectation of dying prior to the age of 30 were significantly associated with suicide attempt (Table 3 ).

Table 2. Bivariate and multivariate associations between suicidal ideation and demographic characteristics, family context and psychosocial correlates among youth living in the slums of Kampala $(N=457)$.

\begin{tabular}{lccc}
\hline \multirow{2}{*}{ Variable } & \multicolumn{3}{c}{ Suicide Ideation } \\
\cline { 2 - 4 } & $\mathbf{\%}$ & OR (95\% CI) & Adj. OR (95\% CI) * \\
\hline Sex (Girls/Boys) & $23.62 / 7.28$ & $\mathbf{1 . 7 3}(\mathbf{1 . 1 0}-\mathbf{2 . 7 3})$ & $\mathbf{2 . 3 1}(\mathbf{1 . 2 6}-\mathbf{4 . 2 3})$ \\
School attendance & 5.52 & $1.46(0.85-2.52)$ & - \\
Both parents dead & 9.33 & $\mathbf{1 . 9 3}(\mathbf{1 . 1 5}-\mathbf{3 . 2 3})$ & $\mathbf{2 . 3 6}(\mathbf{1 . 2 3}-\mathbf{4 . 5 2})$ \\
$\quad 10.89$ & $1.21(0.75-1.95)$ & $1.37(0.78-2.41)$ \\
$\quad$ One parent dead & 10.22 & 1.00 & 1.00 \\
Two parents living & 21.44 & $1.40(0.91-2.16)$ & - \\
Parental physical abuse & 10.80 & $\mathbf{2 . 4 9}(\mathbf{1 . 5 6}-\mathbf{3 . 9 9})$ & $\mathbf{2 . 0 9}(\mathbf{1 . 1 6}-\mathbf{3 . 7 7})$ \\
Apprenticeship skills & 18.75 & $1.17(0.77-1.77)$ & - \\
Any drug use & 6.40 & $\mathbf{2 . 1 7}(\mathbf{1 . 2 6}-\mathbf{3 . 7 4})$ & $1.96(0.90-4.28)$ \\
Any drunkenness & 13.25 & $\mathbf{1 . 9 5}(\mathbf{1 . 2 9}-\mathbf{2 . 9 7})$ & $0.93(0.49-1.75)$ \\
Any STD/HIV & 13.85 & $\mathbf{1 . 5 9}(\mathbf{1 . 0 6}-\mathbf{2 . 3 9})$ & $0.65(0.38-1.11)$ \\
Any traded sex & 14.67 & $\mathbf{2 . 6 6}(\mathbf{1 . 7 4 - 4 . 0 5 )}$ & $\mathbf{1 . 9 5}(\mathbf{1 . 0 9}-\mathbf{3 . 5 1})$ \\
Any rape & 8.07 & $1.12(0.70-1.77)$ & - \\
Sadness & 28.22 & $\mathbf{3 . 3 0}(\mathbf{1 . 8 3}-\mathbf{5 . 9 8})$ & $\mathbf{2 . 4 2}(\mathbf{1 . 2 0}-\mathbf{4 . 8 9})$ \\
Lonely & 29.53 & $\mathbf{5 . 2 4}(\mathbf{2 . 3 3}-\mathbf{1 1 . 7 8 )}$ & $\mathbf{2 . 6 7}(\mathbf{1 . 1 2}-\mathbf{6 . 4 0})$ \\
Expect to die early & 18.97 & $\mathbf{2 . 7 2}(\mathbf{1 . 8 0}-\mathbf{4 . 1 2})$ & $\mathbf{2 . 5 4}(\mathbf{1 . 5 3}-\mathbf{4 . 2 3})$ \\
\hline
\end{tabular}

* Variables included in the multivariate logistic regression analyses are those significantly associated with suicide ideation in the bivariate analyses. All variables included in the adjusted analyses are listed in the table. Statistically significant associations are boldfaced. All variables except for parental living were dichotomized to indicate the presence or absence of the particular risk factor. The reference category for each variable was the absence of the particular risk factor.

\section{Discussion}

In this study of youth who live in the slums of Kampala, it is clear that the mental and physical health needs in this vulnerable population are of grave concern. The overall prevalence of suicide ideation (31\%) was higher in comparison with nationally representative youth in Uganda (22\%) [12]. The underlying factors for the increased burden of suicidal ideation and behavior may be best captured and understood in terms of the family context and the coping mechanism used to face the circumstances of living on the streets and in the slums of Kampala.

First and foremost, more than three quarters of the youth in our survey reported one or both parents deceased, an alarming issue that is likely the key underlying cause of their current living conditions. In our study, reporting that two parents were deceased was significantly associated with suicidal ideation in multivariate analysis. This issue is not unique to the youth in Uganda, since it is estimated that approximately 13 million children in the world have lost either one or both parents to AIDS [2]. However, more than $90 \%$ of these children live in sub-Saharan Africa [2] which makes it a more pressing concern in this region. Moreover a substantial proportion of the youth in our study reported 
having been hit or beaten by their parents and also that their parents had been unable to care for them due to their alcohol use which was an important correlate of suicidal ideation and suicide attempt in multivariate analysis. Parental alcohol abuse is a key concern and a likely contributor to the current living situations for these youth and also because of the documented role of alcohol in child abuse and neglect $[33,34]$. This problem may be particularly salient in Uganda which has the highest estimated per capita consumption of alcohol use world-wide [35]. Trading sex for food, shelter and money and other risky sexual behaviors have been raised as a key concern among vulnerable street youth, not only in sub-Saharan Africa [36], but also elsewhere [37]. Reports of trading sex is typically associated with an urgency of finding food and shelter or money for basic needs and is more commonly reported among street children. In our study, about a third (32\%) of the youth reported having traded sex. Moreover, traded sex was an important and statistically significant correlate of suicide ideation in the multivariate analysis.

Table 3. Bivariate and multivariate associations between suicidal attempt and demographic characteristics, family context and psychosocial correlates among youth living in the slums of Kampala $(N=457)$.

\begin{tabular}{lccc}
\hline \multirow{2}{*}{ Variable } & \multicolumn{4}{c}{ Suicide Attempt } \\
\cline { 2 - 4 } & $\mathbf{\%}$ & OR (95\% CI) & Adj. OR (95\% CI) * \\
\hline Sex (Girls/Boys) & $14.73 / 5.05$ & $1.41(0.83-2.38)$ & - \\
School attendance & 3.74 & $1.53(0.83-2.81)$ & - \\
Both parents dead & 5.53 & $1.51(0.83-2.74)$ & - \\
One parent dead & 7.08 & $1.16(0.67-2.00)$ & - \\
Two parents living & 6.86 & 1.00 & 1.00 \\
Parental physical abuse & 13.93 & $1.48(0.89-2.48)$ & - \\
Parental neglect due to alcohol & 7.71 & $\mathbf{2 . 7 6}(\mathbf{1 . 6 5}-\mathbf{4 . 6 2})$ & $\mathbf{2 . 0 4}(\mathbf{1 . 1 1}-\mathbf{3 . 7 6})$ \\
Apprenticeship skills & 12.44 & $1.43(0.86-2.37)$ & - \\
Any drug use & 4.84 & $\mathbf{2 . 6 0}(\mathbf{1 . 4 5}-\mathbf{4 . 6 6})$ & $1.65(0.78-3.47)$ \\
Any drunkenness & 8.79 & $\mathbf{1 . 9 7}(\mathbf{1 . 2 2}-\mathbf{3 . 1 8})$ & $1.00(0.51-1.95)$ \\
Any STD/HIV & 9.19 & $\mathbf{1 . 6 3}(\mathbf{1 . 0 2}-\mathbf{2 . 6 1})$ & $0.89(0.50-1.58)$ \\
Any traded sex & 9.09 & $\mathbf{2 . 1 2}(\mathbf{1 . 3 2}-\mathbf{3 . 4 1})$ & $1.41(0.77-2.56)$ \\
Any rape & 5.13 & $1.11(0.65-1.90)$ & - \\
Sadness & 18.88 & $\mathbf{5 . 1 9}(\mathbf{2 . 1 9}-\mathbf{1 2 . 3 1})$ & $\mathbf{3 . 2 0}(\mathbf{1 . 3 0}-\mathbf{7 . 8 7})$ \\
Lonely & 18.93 & $\mathbf{5 . 2 2}(\mathbf{1 . 8 5}-\mathbf{1 4 . 7 6})$ & $2.56(0.85-7.71)$ \\
Expect to die early & 12.67 & $\mathbf{2 . 7 2}(\mathbf{1 . 6 7}-\mathbf{4 . 4 0})$ & $\mathbf{2 . 1 8}(\mathbf{1 . 2 5}-\mathbf{3 . 7 9})$ \\
\hline * Variables included in the multivariate logistic & regression analyses are those significantly \\
associated with suicide attempt in the bivariate analyses. All variables included in the adjusted \\
analyses are listed in the table. Statistically significant associations are boldfaced. All variables \\
except for parental living were dichotomized to indicate the presence or absence of the particular \\
risk factor. The reference category for each variable was the absence of the particular risk factor.
\end{tabular}

The mental health needs of these youth were assessed through questions that addressed several related concepts, sadness (76\%), loneliness (82\%), expectations of dying (hopelessness) (44\%), and suicide ideation, attempt and suicidal behaviors. Sadness, loneliness, and expecting to die early were statistically associated with suicide ideation in multivariate analysis. Sadness and expecting to die early were also found to be significantly associated with suicide attempt in multivariate analysis. 
Taken as a whole, these findings underscore great social isolation and despair and calls for more mental health services and interventions for these vulnerable youth. Previous research has shown that street children in Kenya, compared to controls, have high levels of adaptability and flexibility when faced with adversity [38]. However, there may be limits of flexibility because of the possible cumulative effect of victimizations and other adverse health factors that subsequently is expressed as sadness and isolation when there no longer is a social network available for support.

The results of this study should be viewed in the context of several important limitations. First, the study participants were not randomly selected, but were youth who self-selected to attend the drop-in centers and to take part of the study. Therefore, the findings may not be representative of street and slum youth in Kampala and may not be generalizable to populations elsewhere. However, the high response rate in the targeted drop-in centers increases our confidence that the findings are representative of the youth who self-select to attend drop in centers or to seek services more generally. Second, the sample included both street youth who were homeless and youth who lived in the slums but may have had a stable living arrangement. Accordingly, our definition of youth who live in the slums was broad and included a range of circumstances and family contexts (e.g., some of these youth currently lived with two caretakers or in a treatment setting and were relatively well fed and cared for), although circumstances varied significantly. If the study had only included homeless street youth, or if we had been able to differentiate these groups better, the prevalence of the health risk behaviors as well as suicide ideation and attempt would likely have been significantly higher among homeless street youth specifically. However, all youth who participated in the survey were help-seeking youth in that they had participated in services or training classes provided by the UYDEL which may also indicate that these youth are not representative of street youth more broadly and may also at least partially explain why our study included mostly girls. One of the most frequently offered training class by the centers was hairdressing and braiding which is likely to be attended by girls.

Third, because of limited literacy rates, participants were read the questionnaire. The face-to-face interaction between participant and interviewer may have resulted in underreporting of certain high-risk behaviors associated with significant stigma (such as transmission of sexually transmitted diseases or even suicidal ideation or behaviors). While this is an important potential concern because participants (who knew the interviewers) may have been unwilling to disclose sensitive information, it is less likely since the participants selected to attend the drop in centers and discussions of sensitive information was part of many of the services provided. Fourth, during the interviews, participants often provided the answers in Luganda (local language) which required the interviewers to translate the response to English and make the appropriate notations on the questionnaire. This issue was anticipated and discussed during the training of the interviewers and appeared to have been handled appropriately during the data collection by the interviewers who were all proficient and fluent in both spoken and written English.

Fifth, most of the questions regarding mental health factors and high-risk behaviors were selected from previously established self-administered surveys, particularly the Youth Risk Behavior Survey [30] conducted in the U.S. and the Global School-based Student Health Survey [31] conducted primarily in Africa, Asia, and Latin America. In several cases, the wording of the questions used was simplified and the response options narrowed in order to facilitate the administration of the survey questionnaires by the interviewers. As such, the reliability and validity of some of the measures may have been 
altered. Sixth, because of the cross-sectional nature of the survey, the temporal ordering of the psychosocial factors and suicide ideation cannot be determined, nor can causation be inferred. Finally, there were fewer statistically significant correlates of suicide attempts than suicide ideation. This finding is most likely due to the increased severity of attempt versus ideation. However, this finding may also in part be attributable to the lower prevalence of suicide attempt among participants rendering those analyses less strong as indicated by the slightly wider confidence intervals.

Figure 2. Note posted on wall in Drop-in Center, by UYDEL staff, to encourage help-seeking behaviors among potentially suicidal youth.

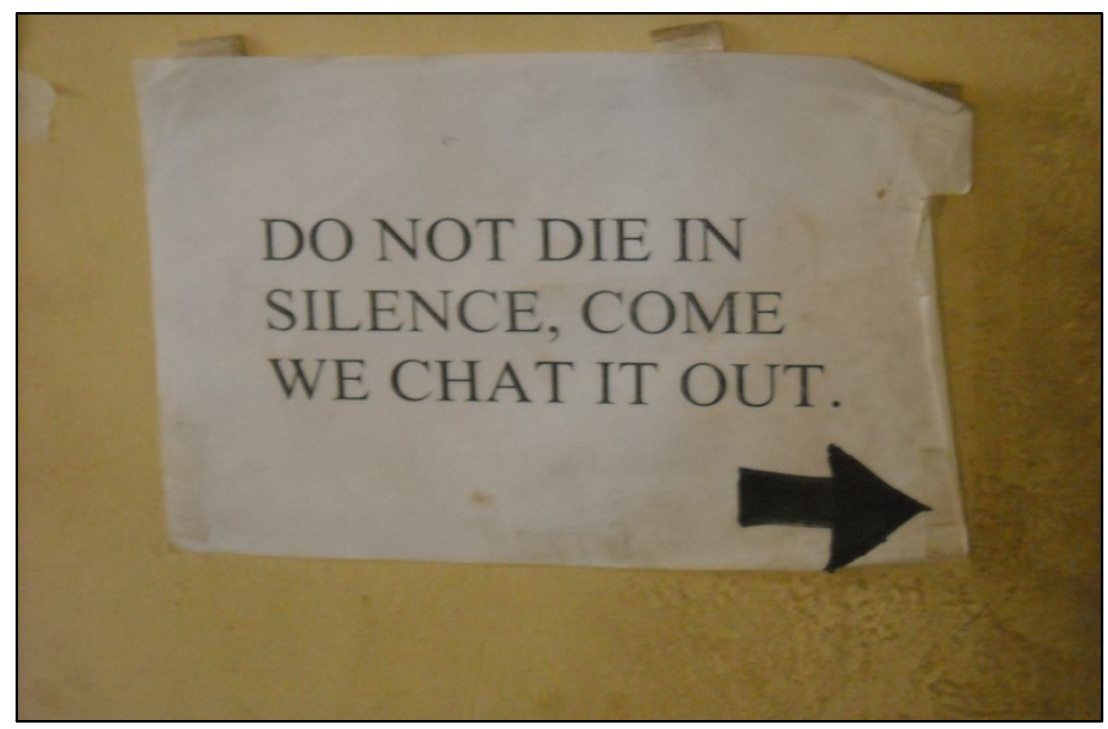

Despite these limitations, the findings clearly underscore grave and unmet needs among these vulnerable youth which has implications for research and practice. While these vulnerable youth may have unique circumstances and needs, overall the psychosocial correlates associated with suicide ideation examined in this study mirror those of previous studies of other African youth [8,10,12,39]. However, additional research is needed to replicate these findings since they are primarily based on a convenience sample of youth who have sought out services offered by a drop-in center. As such, their experiences may be different than that of other youth and should be documented in greater detail and also preferably in a longitudinal cohort to better determine the initiation of risk behaviors and the identification of modifiable factors that may be suitable for prevention.

Future research is also needed to better determine strategies for providing additional services and treatment to these youths who may be difficult to reach. This is particularly troubling given the acute shortage of psychiatrists, psychologists, nurses, and social workers in Africa [40] and in Uganda, more specifically [41]. Moreover, future projection indicates that both self-inflicted deaths will increase substantially by the year 2030 [42] which further underscores the need to strengthen the infrastructure of mental health services and to add capacity, perhaps by incorporating mental health into primary care [42] and increasing the scope and training of lay workers [41]. The staff at UYDEL has sought to implement strategies to encourage help-seeking among potentially suicidal youth (Figure 2); however, more comprehensive efforts, resources and guidance will be needed to reach more youth. 
In terms of the implication for practice, it is important to recognize that evidence-based strategies used elsewhere [43] may not be relevant for a low-income country such as Uganda or for vulnerable youth with particular needs and circumstances. That said, brief interventions and contact following suicide attempts which have been found to be effective for reducing subsequent suicide mortality [43] may possibly be adapted to local conditions and may even be applied in a primary prevention mode. Moreover, other strategies have been suggested for the development of child mental health services in low income countries [44] including school based mental health programs [45] that may also be promising for adaptation to be delivered to youth who seek services in drop-in centers. Recent findings have emphasized that child and mental health efforts begin with awareness and that schools in many countries are willing to support positive change to address mental health needs [46]. These strategies may also be adapted for other settings outside of schools that provide services to vulnerable youth.

Given the limited healthcare resources available for treatment and prevention of infectious and other diseases, it is clear that public health issues such as suicide and self-directed violence have been given less priority [47]. However, the findings from this study can be used to advocate the urgency for providing more resources and services to these vulnerable youth, most of which have lost one or more parents and have faced significant adverse childhood experiences. Because of the significant burden of these youth, their circumstances will further compound existing problems including the spread of sexually transmitted diseases. As such, resources need to provide basic shelter and services to them, but also seek ways to reduce the social isolation and hopelessness that they report and emphasize primary prevention of high risk behaviors. The priority of providing more services to vulnerable youth needs to be considered complimentary to, and not competing with, other prevention efforts underway to address HIV/AIDS and other critical health problems including malaria, hunger and poverty. Finally, as has been called for previously, it is important to create a national suicide prevention plan with local community support [48] so that future interventions, policies, and resource allocation can yield the impact needed and to improve the conditions and health outcomes of these vulnerable youth.

\section{Conflicts of Interests}

There are no conflicts of interests to disclose.

\section{Acknowledgment}

The authors thank the entire research team at the Uganda Youth Development Link team for their work. We also thank all of the survey participants for their time and willingness to participate in this study. Moreover, we gratefully appreciate the funds we obtained to support this project from the Office of International Initiatives at Georgia State University as well as the leveraged funds obtained in collaboration with the Emory Center for Injury Control funded by the Centers for Disease Control and Prevention Grant\# 5R49CE001494. 


\section{References}

1. World Health Organization. Suicide prevention (SUPRE); 2011. Available online: http://www.who.int/mental_health/prevention/suicide/suicideprevent/en/ (accessed on 11 October 2011).

2. Krug, E.G.; Dahlberg, L.L.; Mercy, J.A.; Zwi, A.B.; Lozano, R. World Report on Violence and Health; World Health Organization, Geneva, Switzerland, 2002. Available online: http://whqlibdoc.who.int/publications/2002/9241545615_eng.pdf (accessed on 11 October 2011).

3. Wasserman, D.; Cheng, Q.; Jiang, G.-X. Global Suicide rates among young people aged 15-19. World Psychiatry 2005, 4, 114-120.

4. Patton, G.C.; Coffey, C.; Sawyer, S.M.; Viner, R.M.; Haller, D.M.; Bose, K.; Vos, T.; Ferguson, J.; Mathers, C.D. Global patterns of mortality in young people: A systematic analysis of population health data. Lancet 2009, 374, 881-892.

5. Ovuga, E.; Boardman, J.; Wassermann, D. Prevalence of suicide ideation in two districts of Uganda. Arch. Suicide Res. 2005, 9, 321-322.

6. Bertolote, J.; Fleischmann, A. A Global Perspective on the Magnitude of Suicide Mortality. In Suicidology and Suicide Prevention: A Global Perspective; Wasserman, D., Wasserman, C., Eds.; Oxford University Press: Oxford, UK, 2009; pp. 91-98.

7. Schlebusch, L.; Burrows, S.; Vawda, N. Suicide Prevention and Religious Traditions on the African Continent. In Suicidology and Suicide Prevention: A Global Perspective; Wasserman, D., Wasserman, C., Eds.; Oxford University Press: Oxford, UK, 2009; pp. 63-69.

8. Omigbodun, O.; Dogra, N.; Esan, O.; Adedokun, B. Prevalence and correlates of suicidal behaviour among adolescents in Southwest Nigeria. Int. J. Soc. Psychiatry 2008, 54, 34-46.

9. Joe, S.; Stein, D.J.; Seedat, S.; Herman, A.; Williams, D.R. Prevalence and correlates of non-fatal suicidal behavior among South Africans. Br. J. Psychiatry 2008, 192, 310-311.

10. Muula, A.S.; Kazembe, L.N.; Rudatsikira, E.; Siziya, S. Suicidal ideation and associated factors among in-school adolescents in Zambia. Tanzania Health Res. Bull. 2007, 9, 202-206.

11. Hjelmeland, H.; Knizek, B.L.; Kinyanda, E.; Musisi, S.; Nordvik, H.; Svarva, K. Suicidal behavior as communication in a cultural context: A comparative study between Uganda and Norway. Crisis 2008, 29, 137-144.

12. Swahn, M.H.; Bossarte, R.M.; Eliman, D.M.; Gaylor, E.; Jayaraman, S. Prevalence and correlates of suicidal ideation and physical fighting: A comparison of students in Botswana, Kenya, Uganda, Zambia and the Unites States. Int. Public Health J. 2010, 2, 195-205.

13. Swahn, M.H.; Bossarte, R.M.; Eliman, D.M; Gaylor, E.; Walingo, M.K. Associations between hunger and emotional and behavioral problems: A comparison of students in Botswana, Kenya, Uganda, Zambia and the Unites States. Int. Public Health J. 2010, 2, 185-194.

14. Food and Agriculture Organization. The State of Food Insecurity in the World 2011; 2011. Available online: http://www.fao.org/docrep/014/i2330e/i2330e00.htm (accessed on 11 October 2011).

15. Mufune, P. Street Youth in Southern Africa; Blackwell Publishers: Malden, MA, USA, 2000.

16. Chigunta, F. The Socio-Economic Situation of Youth in Africa: Problems, Prospects and Options; 2002. Available online: www.yesweb.org/gkr/res/bg.africa.reg (accessed on 11 October 2011). 
17. Worldwatch Institute. Uganda on Track to Have World's Highest Population Growth; 2011. Available online: http://www.worldwatch.org/node/4525 (accessed on 11 October 2011).

18. Lieb, R.; Meinlschmidt, G.; Araya, R. Epidemiology of the association between somatoform disorders and anxiety and depressive disorders: An update. Psychosom. Med. 2007, 69, 860-863.

19. Souza, R.; Porten, K.; Nicholas, S.; Grais, R. Outcomes for street children and youth under multidisciplinary care in a drop-in centre in Tegucigalpa, Honduras Int. J. Soc. Psychiatry 2010. Available online: http://isp.sagepub.com/content/early/2010/09/13/0020764010382367 (accessed on 11 October 2011).

20. UNICEF Challenges and Opportunities-A UNICEF Report on Street Children; UNICEF: New Delhi, India, 2001.

21. Sherman, S.; Plitt, S.; Hassan, S.U.; Cheng, Y.; Zafar, S.T. Drug use, street survival, and risk behaviors among street children in Lahore, Pakistan. J. Urban Health 2005, 82, 113-124.

22. le Roux, J.; Smith, C.S. Causes and characteristics of the street child phenomenon: A global perspective. Adolescence 1998, 33, 683-688.

23. Kidd, S.A.; Carroll, M.R. Coping and suicidality among homeless youth. J. Adolesc. 2007, 30, 283-296.

24. Yoder, K. Comparing suicide attempters, suicide ideators, and nonsuicidal homeless and runaway adolescents. Suicide Life Threat. Behav. 1999, 29, 26-36.

25. Roy, E; Haley, N.; Lecierc, P.; Sochanski, B.; Boudreau, J.; Boivin, J. Mortality in a cohort of street youth in Montreal. JAMA 2004, 292, 569-574.

26. Molnar, B.E.; Shade, S.B.; Kral, A.H.; Booth, R.E.; Watters, J.K. Suicidal behavior and sexual/physical abuse among street youth. Child Abuse Negl. 1998, 22, 213-222.

27. Greene, J.M.; Ringwalt, C.L. Youth and familial substance use's association with suicide attempts among runaway and homeless youth. Subst. Use Misuse 1996, 31, 1041-1058.

28. Kidd, S.A. Youth homelessness and social stigma. J. Youth Adolesc. 2007, 36, 291-299.

29. UYDEL. Available online: http://www.uydel.org (accessed on 7 February 2012).

30. Centers for Disease Control and Prevention (CDC). Youth risk behavior surveillance: United States 2005. MMWR 2006, 55, 1-108.

31. Global School-Based Student Health Survey. Atlanta (GA): Centers for Disease Control and Prevention. Available online: http://www.cdc.gov/GSHS/ (accessed on 7 February 2012).

32. World Health Organization. Working with Street Children: A Training Package on Substance Use, Sexual and Reproductive Health Including HIV/AIDS and STDs; 2000. Available online: http://www.who.int/substance_abuse/activities/street_children/en/index.html (accessed on 7 February 2012).

33. Famularo, R.; Stone, K.; Barnum, R.; Wharton, R. Alcoholism and severe child maltreatment. Am. J. Orthopsychiatry 1986, 56, 481-485.

34. Widom, C.S.; Hiller-Sturmhofel, S. Alcohol abuse as a risk factor for and consequence of child abuse. Alcohol Res. Health 2001, 25, 52-57.

35. World Health Organization. Global Status Report on Alcohol 2004, 2nd ed.; World Health Organization: Geneva, Switzerland, 2004. Available online: http:/www.who.int/substance_abuse/ publications/en/Alcohol\%20Policy\%20Report.pdf (accessed on 7 February 2012). 
36. Ntozi, J.P.M.; Mulindwa, I.N.; Ahimbisibwe, F.; Ayiga, N.; Odwee, J. Has the HIV/AIDS epidemic changed sexual behaviour of high risk groups in Uganda? Afr. Health Sci. 2003, 3, 107-116.

37. Potdar, R.; Mmari, K. Factors influencing sexual initiation, multiple partners and condom use among male slum youth in Pune, India. Glob. Public Health 2010, 6, 843-858. Available online: http://dx.doi.org/10.1080/17441692.2010.516759 (accessed on 7 February 2012).

38. Ayuku, D.; Devries, M.W.; Arap Mengech, H.N.K.; Kaplan, C.D. Temperament characteristics of street and non-street children in Eldoret, Kenya. Afr. Health Sci. 2004, 4, 24-30.

39. Page R.M.; West, J.H. Suicide ideation and psychosocial distress in sub-Saharan African youth. Am. J. Health Behav. 2011, 35, 129-141.

40. Saxena, S.; Thornicroft, G.; Knapp, M.; Whiteford, H. Resources for mental health: Scarcity, inequity and inefficiency. Lancet 2007, 370, 878-889.

41. Ovuga, E.; Boardman, J.; Wassermann, D. Integrating mental health into primary health care: Local initiatives from Uganda. World Psychiatry 2007, 6, 60-61.

42. World Health Organization. World Health Statistics; 2008. Available online: http://www.who.int/whosis/whostat/2008/en/index.html (accessed on 23 October 2011).

43. Fleishmann, A.; Bertolote, J.M.; Wasserman, D.; de Leo, D.; Bolhari, J.; Botega, N.J. Effectiveness of brief intervention and contact for suicide attempters: A randomized controlled trial in five countries. Bull. World Health Organ. 2008, 86, 657-736.

44. Omigbodun, O. Developing child mental health services in resource-poor countries. Int. Rev. Psychiatry 2008, 20, 225-235.

45. Izbeziako, P.I.; Omigbodun, O.O.; Bella, T.T. Assessment of need for a school-based mental health programme in Nigeria: Perspectives of school administrators. Int. Rev. Psychiatry 2008, 20, 271-280.

46. Hoven, C.W.; Doan, T.; Nusa, G.J.; Jaliashvili, T.; Duarte, C.S.; Ovuga E.; Ismayilov, F.; Rohde, L.A.; Dmitrieva, T.; Du, Y.; et al. Wolrdwide child and adolescent mental health begins with awareness: A preliminary assessment in nine countries. Int. Rev. Psychiatry 2008, 20, 261-270.

47. Lett, R.R.; Kobusingye, O.C.; Ekwaru, P. Burden of injury during complex political emergency in Northern Uganda. Can. J. Surg. 2006, 49, 51-57.

48. Beautrais, A.L.; Mishara, B.L. World suicide prevention day: "Think Globally, Plan Nationally, Act Locally". Crisis 2008, 29, 59-63.

(C) 2012 by the authors; licensee MDPI, Basel, Switzerland. This article is an open access article distributed under the terms and conditions of the Creative Commons Attribution license (http://creativecommons.org/licenses/by/3.0/). 